\title{
Mysticism in Tibetan Buddhism. A study into the Path of Insight
}

\section{KEYWORDS}

mind, preliminary practices, tranquility meditation, penetrating insight meditation, the Path of Insight, the Path of Liberation

\begin{abstract}
Wysocki Adam, Mysticism in Tibetan Buddhism. A study into the Path of Insight. Culture - Society - Education no 2(16) 2019, Poznań 2019, pp. 183-201, Adam Mickiewicz University Press. ISSN 2300-0422. DOI 10.14746/ kse.2019.16.12.
\end{abstract}

The Path of Insight is a spiritual path of Tibetan Buddhism tradition. The fundamental part consists of three elements, such like: preliminary practices, the tranquility meditation and the penetrating insight meditation. However, counted three parts one ought to perceive as aspects of one process aiming to realize of the soteriology purpose. The achievement of the non-dual state has its own development process, which consists experience of the non-dual state, stabilise it and then development of it. Outline of development process is contained in the Path o Insight and relies on exceeding of subjective-objective divisibility. It is perceived as an effect of the ignorance of true nature of the individual. The achievement of the non-dual state, that is nature of the mind (tib. sems nyid) constitutes the purpose of the Path of Insight and it is described by concept-symbol called mahamudra.

The following paper is intended to provide an outline of the Path of Insight, as one of the basic meditation practices represented in Tibetan Buddhism. Even though the ideas discussed pertain to the Tibetan spiritual tradition as a whole, the main topic at hand, as well as the applied categorisation is most significantly related to 
the teachings of the Kagyu school (Tib. bka' brgyud) ${ }^{1}$ of Tibetan Buddhism. This issue falls into the broad research category of mysticism, since it is with regards to such a type of experience that is identified as the supreme truth, ultimate or absolute reality, and the path leading to it, i.e. all practices aimed at the achievement of its direct experience (Podsiad, Więckowski, 1983: 218-219). The work below was predominantly based on the characteristic and structure if the Path of Insight as given in the writings of Wangchuk Dorje, the 9th Karmapa Lama The Mahamudra Eliminating The Darkness Of Ignorance, as well as other historical sources and contemporary works regarding the issue at hand.

\section{The general tenets of Buddhist Tantrism}

To give an account of the Path of Insight requires a degree of introduction into the basic tenets of Tantric practice, in order to portray the ideological context wherein the issue at hand is realised. Foremost, it should be noted after Michael von Brück, that the Tibetan Buddhism forms an exquisitely intricate set of religious and philosophical beliefs, and offers a wide range of means to pursue the soteriologic goal and achieve it in a shorter timespan than would be the case with other paths of spiritual development. To quote the said author on Vajrayana (Skt. Vajrayāna 'Diamond Vehicle' or 'Thunderbolt Vehicle'):

(...) an extraordinarily intricate religion, subtle in its philosophical systems, detailed in its view on psychology and precise in the description of its symbols and visualisation techniques, meant to release the human being's own power to transform themselves, become wholly mindful and achieve the state of Buddha over the shorter path, i.e. In this life. (Brück, 1997a: 47)

This is made possible by the application of more efficient and specific methods described in the Tantras, the enlightened texts of Tantrism. Elsewhere in the above cited work, the author indicates that in Tibetan Buddhism 'Tantra' (Tib. rgyud) is understood as a continuum, similar to a matrix of consciousness, encompassing both mundane personalities and Buddha himself, and founded upon the reality of 'clear light' (Tib. 'od gsal). It includes two aspects, which are: (1) the objective aspect, the voidness (Skt. śünyatā, Tib. stong pa) of reality in relation to the inherent

${ }^{1}$ Wylie Transliteration was used throughout for Tibetan terms, while in the case of Sanskrit the standarised academic spelling was applied. The foreign terms are given in italics and introduced by a Tib. or Skt. abbreviation respectively. Occasionally, the English spelling of common terms was used. Where the term is part of a quote, the author's original spelling was retained. 
existence, and (2) the subjective aspect, the knowledge awareness which is capable of experiencing this voidness (Brück, 1997b²: 474). Moreover, and more precisely, it can be indicated that the Tantric tenets claim that all dualities in the appearances of existence ultimately compensate one another into unity, which is a notion widely used in sadhana (Skt. Sādhanā), ādhanā), the Tantric spiritual practice. Mircea Eliade described this in the following way

(...) the absolute reality, the Urgrund, contains in itself all dualities and polarities, but reunited, reintegrated, in a state of absolute Unity (advaya). (...) The purpose of tantric sadhana is the reunion of the two polar principles within the disciple's own body. (Eliade, 1997: 221)

This Urgrund, the primordial foundation, is the Adibuddha (Skt. A $d h i-B u d-$ dha - 'Primordial Buddha'). All beings possess the Buddha-nature which is the foundation of their enlightenment, while the absolute truth manifests itself in the various aspects of reality, due to which its various forms may be used to achieve the integration, leading to such constitution of consciousness that becomes an expression of the absolute, i.e. the realisation of the non-dual state of mind (Zotz, 2007: 160). The necessity of existence, of remaining in a conditioned state, the sansara, is a result of one's ignorance (Skt. avidyā, Tib. ma rig pa) of their own true, inherent nature. Moreover, Tantra realises the principle of the identicalness of mind, or consciousness, and the broadly understood energy (Skt. prana, Tib. rlung), where the varying levels of its subtlety are the vehicle to their respective states of consciousness. The means applied in order to master the element of energy, i.e. to initiate subtle and very subtle energies, are called the Path of Methods, while the practices aimed directly at the mastering and recognition of the nature of mind are realised on the Path of Insight, also called the Path of Liberation (Chang, 1987: 18-22). It should be noted that both Paths ultimately lead to the realisation of the mahamudra (lit. 'The Great Seal' or 'The Great Symbol', Skt. mahāmudrā, Tib. chakgya chenpo), which is their soteriologic goal, even though the Path of Insight itself is also regarded as the practice of mahamudra (Lama Tashi Namgyal, 2003: 1). The status of this notion reflects the crucial tenet of Vajrayana, which attributes the essential meaning of the non-dual state and the non-factuality of all polar dualities in existence. With regards to the understanding of this term in Tibetan Tantrism, Geshe Ngawang Dhargyey points to the following:

the hidden etymology of the Tibetan term for Mahamudra, Chag-gya chen-po, is as follows: ch'ag means 'void', gya 'liberation from samsara', and chen-po is the 'great achievement of absolute nonduality' (Skt. juganaddha), i.e. the union of realisation of void and the liberation from samsara. (Ngawang Dhargyey, 1995: 5-6) 
A similar explanation can be found i.a. in Mahāmudrātilaka-tantra: chak stands for awareness of emptiness, gya signifies its intrinsic quality that transcends existential duality, chenpo symbolizes the union of the two (Dakpo Tashi Namgyal, 2006: 92). The transcendence of the subject-object opposition, characteristic of the dual state of existence, is also mentioned in Guhyasamāja-tantra. Furthermore, it emphasises the denial of a substance-attribute (Skt. Anatman),), the ultimate unity of samsara and nirvana, as well as the unity of the skillful means (Skt. upaya) and wisdom (Skt. prajña), realised within this 'supreme meditation' as it is called (Dakpo Tashi Namgyal, 2006: 92). With regards to non-Tantric understanding of the term mahamudra, i.e. at the level of sutras, the discrepancies are quite elusive in literal juxtaposition and only come to the fore when the broader context of meaning is taken into account, revealing another level of the understanding of the voidness (Skt. śünyatā) and the considerable difference of the Tantra-specific methods. As explained by Geshe Ngawang Dhargyey:

There is no difference between voidness cognized by tantra methods and that by sutra ones. The difference lies in the level of mind that non-conceptually cognizes it. With the anuttarayoga tantra methods, voidness is non-conceptually cognized by the subtlest level of consciousness accessed by causing the energy-winds to enter, abide, and dissolve in the central energy-channel. With the sutra ones, it is non-conceptually cognized by a grosser level of mind. (Ngawang Dhargyey, 1995: 6)

The author refers here to the assumption of the existence and initiation of subtle energies, as the foundation for their respective levels of consciousness. Such methods may well be used, even though they are not part of the main practice in the Path of Insight. As can be seen in the above, the main task of a human being, according to the Buddhist Tantra, is to transcend the subject-object opposition and the realisation of the non-dual state of mind. These two elements must ultimately become integrated within an individual, which requires appropriate means to be used, and practices to be pursued, such as the ones discussed below Path of Insight. Its general characteristic is given by Lama Ole Nydahl, along with precepts for the appropriate means and the nature of the experience itself.

Both conceptual and direct methods are used to allow the mind to achieve a state of tranquillity. At a certain point, the experiencing individual, the experienced phenomena and the very act of perception are meant to become one, resulting in the penetrating insight. (Lama O. Nydahl, 1999: 19) 
What follows, is that the Path of Insight aims at the recognition of the ultimate foundation of mind (Skt. citta, Tib. sems), i.e. the realisation of the nature of mind (Skt. cittata, Tib. sems nyid), which is not merely theoretical knowledge, but a direct experience resulting from individual meditation.

\section{Preliminary practices}

The core practice should be preceded by the appropriate preliminary practices (Skt. pürvaka, Tib. sngon 'gro). They fulfil a preparatory function and can be compared to rising a foundation, upon which the future enlightenment is to be built. Their main goal is to cleanse the mind of conceptual barriers and to accumulate the merit which is to grant success in the core practice. Even though their status is 'preliminary', they are an essential introduction and a foundation for further practice, adding to its effectiveness. The formal term for these practices can prove misleading. They should never be regarded as inferior, nor be discontinued after completion. Several of these practices, such as the Guru Yoga, may be continued during the core practice. Preliminary practices can be divided into common and extraordinary. They are eight in total, four of both types. The latter type includes:

- Taking Refuge and developing the Enlightened Motive (Skt. Bodhicitta),), which relates to the inclusion of the Three Jewels in one's life. The Refuge is taken in Buddha, the goal, in Dharma (Skt. Dharma),), the Path, and in Sangha (Skt. Sangha),), the Community of those who fulfil Dharma's requirements. (Additionally, in Vajrayana one also takes refuge in the Three Jewels, i.e. the Lama, Yidam and Dharmapala (Tenga Rinpoche, 1994: 129, 134). Bodhicitta on the other hand is an attitude of the mind aspiring to enlightenment (Tenga Rinpoche, 1994: 123);

- Vajrasattva Meditation (Skt. Vajrasattwa, Tib. rdo rje sems dpa), which includes the visualisation, on the crown of one's head the Guru as Vajrasattva (a form adopted by Buddhas for purification and the cleansing of obscurities), with the recitation of a 100- or 6-syllable mantra, which should be repeated 100,000 times;

- Mandala Offering, meant to accumulate the merit allowing for the accomplishment of the scheduled goal, represents the full devotion of the practitioner to the idea of enlightenment and is completed by visualisation of with the use of appropriate tools, and by the 100,000 repetitions of a certain verse; 
- Guru Yoga, the most private practice, when a personal bond with the master becomes established. Good relationship with the root Guru enables more efficient cooperation, and thus more effective progress along the spiritual path. This practice is based upon the visualisation technique, with the Guru on the crown of one's head in the appropriate form (alone or with their retinue of e.g. his predecessors within the same tradition), and the meditation upon the fact that the root Guru unites and personifies all the previous teachers as well as the Three Jewels (Buddha, Dharma and Sangha). The adept then becomes one with their guru, 'dissolving' the master in themselves to the accompaniment of a suitable verse (Beru Khyentse Rinpoche, 1993: 10-20).

The preliminary practices of the common type provide topics for consideration, meant to raise the practitioner's awareness of their own current situation and to display the problem at hand, so that the previous habits can be replaced with new ones, furthering the pursuit of enlightenment. They are a kind of philosophical reflection upon the meaning of life and the true nature of reality. Describing the given situation of a human being, they help them become fully aware of it and, by means of emphasising its essential traits, encourage the ascension upon the spiritual path which would allow the practitioner to transcend the indicated conditioning. The common preliminaries are comprised of certain topics to consider, which demonstrate their common background by indicating the traits of conditioned reality, i.e. samsara. To quote Beru Khyentse Rinpoche: "As a common-ground, they form the context for all Buddhist practice and help set your motivation." (Beru Khyentse Rinpoche, 1993: 10).

The topics for reflection are given in the names of particular practices. There are four in total: death and impermanence, the law of cause and effect (karma), the disadvantages of samsara (the conditioned state of suffering), and the precious human rebirth.

The extraordinary preliminaries on the other hand, are embedded in the system and require taking up regular practice with formal engagement. Beru Khyentse Rinpoche in his general characteristics of the extraordinary practices, said:

The purpose of preliminaries is to eliminate or purify yourself of the obstacles that might hinder your practice and to accumulate the merit that will bring you success Prostration and Vajrasattva meditation accomplish the former, while Mandala Offering and Guru-yoga the latter. (Beru Khyentse Rinpoche, 1993: 10)

It should be noted, that they teach discipline and are a formal way of inclusion into Sangha. Their goal is also to improve certain internal qualities, such 
as renunciation and devotion (Khenchen Thrangu Rinpoche, 2003: 128), which influence the achievement of the disposition that enables the core practice to be realised.

\section{Tranquillity meditation}

The tranquillity meditation (Skt. śamatha, Tib. zhi gnas) initiates the core practice of the Path of Insight. It contains certain recommendations pertaining to the body, but focuses on a number of mental techniques. With regards to the former, the correct physical positioning serves to aid the meditation practice. This is known as the Seven-Point Posture of Vairochana (Khenchen Thrangu Rinpoche, 2003: 26-27; Ngawang Dhargyey, 1995: 9), which enables the appropriate energy flow (Skt. prana, Tib. rlung) throughout the energy channels (Skt. nadi, Tib. Rtsa), and in turn impacts on the efficiency of the practice itself.

The first step of the mind tranquillity meditation is to settle the mind on an object. This can be any kind of sensory object. One should focus their attention on it for as long as possible, until it becomes tiresome or irritating. In order to view such an object in the same way throughout the observation, without lapses into distraction, one needs to cut themselves off from the train of thought and to restrain mental activity. The choice of objects to settle on may well follow individual preferences. According to Karmapa one can even choose an imagined object: "You can also focus in front of you on either a writte or visualised white syllable OM, red AH and blue HUM, (...) or on white, red and blue dots, whichever suits you." (9th Karmapa Wangchuk Dorje, 1993: 34).

When a degree of skill is achieved in settling on a visual object, it is recommended to shift and focus on a certain sound or smell. The next step is to focus on no object, described by Karampa as follows: "As for directing your mind on no basis or object, you should stare blankly into space straight in front of you with opened eyes and not direct your mind at any object whatsoever." (9th Karmapa Wangchuk Dorje, 1993: 39).

In order to realise the precept of 'equanimity', it is essential to free oneself from hope and anxiety regarding the results of the practice, from assessing the current situation and from any kind of mind-wandering. This, however, should not lapse into a state of stupor or blank-mindedness, but rather focus on mindful awareness of one's surroundings, without becoming 'attached' to anything in particular. Focusing on the breath is the last exercise of mind tranquillity practice. This is were, the tenet of the inseparability of consciousness and ener- 
gy is applied. Due to the fact that breathing techniques can be used to regulate the entire complicated system of the energy-winds upon which the mind 'rides', settling on the breath and controlling it 'automatically' affect the consciousness in a similar manner. The method of counting one's breaths may be applied here. With a degree of experience, one should try to hold the air in their lungs before exhaling, and ultimately progress to the vase-breath technique. This type of breathing, among other characteristics, is unique in its efficiency to hold (condense) the air in one's body over extended periods of time (9th Karmapa Wangcziuk Dordże, 1993: 41).

The main challenge to an adept in the tranquillity practice is the maintenance of the required state of settled mind, which is the prerequisite for further progress. Initially, the greatest danger lies in the tendencies to let the thoughts wander, to be 'elsewhere' or to occupy the mind with anything but the focus of the practice. The above quoted author suggests short and frequent sessions for beginners, in order to avoid dullness and fatigue. Another danger lies in becoming preoccupied with the results of the practice, and the associated hope or anxiety. This is yet another form of 'mind wandering' away from being 'here and now', which can thwart the essential concentration. This can be countered by the recognition of such concepts 'at their foundation' as distractions, leading away from the core practice. Finally, a mind overly tense or loose can hinder the progress of the exercise. In the case of the former, the mind 'grasps at' the core practice to tightly; in the latter the mind can lapse into dullness and unawareness. With regards to the hindrances of meditation practice, Lama Ole Nydahl convincingly remarks:

First and foremost, the mind may remain settled for only as long as it remains fully aware. Otherwise, the spiritual life of the practitioner may lapse into a judgemental pursuit of thoughts or the dull effect of a 'matt glass', instead of experiencing the luminosity of a brilliant diamond. (Lama O. Nydahl, 1999: 19)

When such symptoms of excessive tension or looseness are noticed, in order to relieve the agitation, Karmapa suggests to visualise a black, lustrous, spherical dot the size of a pea at the point in front of you where the folded legs touch the seat. In the case of dullness on the other hand, the mind can be encouraged to greater awareness by visualising a similar dot, but white, shining and placed at the middle of the brow, or to resort to physical exercise (9th Karmapa Wangchuk Dorje, 1993: 37). This practice should be continued until the mind reaches the state of such tranquillity, that the emerging thoughts or performed activities do not break the concentration, and that this state can be upheld in an 'effortless' manner. A brief description of this practice's goal and its related difficulties is as follows: 
According to its definition, mental quiescence is a state in which your mind is quieted of all mental wandering, be it thoughts or grasping at defining characteristics. It is a placement of the mind in single-pointed concentration on the non-conceptual nature of things and is free of mental dullness, agitation and foggy-mindedness. (9th Karmapa Wangchuk Dorje, 1993: 45)

Such ability allows to retain the settling of one's mind regardless of circumstances one might find themselves in.

Following to the above, and in accordance with the suggestions of Khenchen Thrangu Rinpoche, the main obstacle in the mind tranquillity meditation is the inability to maintain the presence in 'here and now', without too much thought traffic ('mind wandering'). The author advises neither to remember the past, nor think upon the future. This seems to be a complex problem: (a) it is linked to the common tendency of being drawn to pleasant things and situations and repulsed from unpleasant experiences which cause suffering, and furthermore (b) there exists a certain, constant tendency to conceptualisation as such. Within the framework of mind tranquillity meditation, this is with regards to any and all objective content appearing within the six consciousnesses, i.e. the consciousness of each of the senses and the mind-consciousness (also regarded as a sense) (Khenchen Thrangu Rinpoche, 2003: 28-30).

Mind tranquillity meditation includes three phases of development, which can also be described as the three parts it can be divided into. The first pertains to the attempts to 'grasp a yet ungrasped mind'; and the individuals experiencing multiple unsubtle thoughts, who struggle to achieve a state without any hindering mental activity during their formal meditation sessions. A state of the mind attempting to realise this first phase of tranquillity meditation is compared to a steep mountain waterfall, which is meant to symbolise the coarseness and multitude of thoughts (9th Karmapa Wangchuk Dorje, 1993: 42; Khenchen Thrangu Rinpoche, 2003: 51).

The following phase focuses on maintaining the tranquillity of mind during the meditation practice. At this stage the agitated thought traffic subsides. According to Karmapa, the practice can then be compared to a gentle-flowing, mighty river, which may occasionally become turbulent but settles rapidly. At this stage the practitioner's efforts focus on countering the emerging turbulences, i.e. on recognising the movement of thoughts as unwanted and neutralising it, which is accomplished by becoming aware of one's passing thoughts and not following them. Thus: "(...) all thoughts, both coarse and subtle, set (like the sun) and settle in equipoise into a non-conceptual state" (9th Karmapa Wangchuk Dorje, 1993: 42). 
The third phase furthers the goal of the second, and transfers this practice beyond the ramifications of a formal meditative session. The first and second phase both refer to a given meditation period, whilst the third phase expands the periods spent meditating with the use of the already learned skills. Mind tranquillity transcends its own boundaries and in a natural manner flows beyond the framework of meditation sessions, this becoming increasingly "effortless". The way of conduct can be summarised as maintaining a state of mind in-between excessive tension and looseness, and requires brief but regular sessions, which would allow to achieve a clear, penetrating presence while preventing dullness and fatigue; otherwise the practice may become ineffective. As it would seem, the crucial moment in the mind tranquillity meditation arrives when one becomes able to manage their emerging thoughts Karmapa concludes that:

You will never be able to reach a non-conceptual state by blocking conceptual thoughts. Take these very thoughts themselves as your object and focus right on them. Conceptual thoughts dissolve by themselves. When they clear away, a non-conceptual state will dawn. (9th Karmapa Wangchuk Dorje, 1993: 44)

Every thought has its own content, it refers tosomething, which can spark desire or 'attachment' to a certain mental object. On the other hand, artificial blocking of mental activity is quite futile with regards to achieving the desired effect, as the very act of blocking thoughts is in itself a mental activity. A Karampa remarks, it is rather a certain awareness skill, the ability to perceive thoughts as they emerge and see them for what they are, that can cause the thoughts to dissolve, since they are in fact, merely mental phenomena. It is thus, both a practical skill, and an achievement of the goal of the mind tranquillity meditation.

\section{Penetrative insight meditation}

The other part of the Path of Insight, the penetrative insight meditation (Skt. vipaśjana, Tib. lhag mthong), relies on the recognition of the true nature of the mind from the perspective of five different studies, which are an analytical way of insight into the states or situations that affect the mind. Such study can also be conducted simultaneously with the mind tranquillity practice. However, without the skill to maintain the mind quiescence and one-pointedness regardless of circumstances, it is practically impossible to practice penetrative insight in any but the most superficial way. This is due to the fact that the realisation of the former practice directly influences the efficiency of the latter. The skill to maintain the one-pointedness of 
the mind allows the practitioner to reach the essential level of ability to recognise even the most subtle concepts emerging in the mind, which in turn affects the efficiency of the recognition of its true nature through observation and analytical insight.

The posture required at this stage is the same essential bodily posture as mentioned previously, the way of looking is very different though: "Your eyes should not be blinking, wavering to and fro or changing focus, but should be staring intensely with sharp focus directly ahead (slightly upwards) at the empty space before you." (9th Karmapa Wangchuk Dorje, 1993: 48).

The mind should be placed in a faultless state of 'bare non-conceptuality' and then become scrupulously looked at, being the first of the 'situations' to study. What fallows is a meticulous analysis, meant to perceive any defined qualities. A series of questions will arise, regarding the nature of the mind: does it have a colour, a form, a shape? Is it outside or inside? Is its nature a total blackness, or is it a clear, vivid brightness? etc. Finally, a conclusion should arrive that::

The nature of a settled mind is a clear, vivid luminosity, not a blank emptiness. In this settled state, there is a consciousness which although it cannot be identified (as this or that) is still a vividness, a pristine purity, a resplendence. (...) it just cannot be put into words nor identified as this or that. (9th Karmapa Wangchuk Dorje, 1993: 57)

It has no colour nor shape, cannot be identified as something, yet it causes all other things to appear "clear and unobscured". This consciousness is invariably present, if not always recognised (9th Karmapa Wangchuk Dorje, 1993: 57).

The following situation to analyse is the'moving' or thinking mind. The study of the way mental formations and intellectual concepts emerge and dissolve should lead to a conclusion that: "There is no (...) difference in the nature [of the mind] between thought and its content, between a mind settled or moving, past or current, nor between past and current thoughts." (9th Karmapa Wangchuk Dorje, 1993: 61).

The following two studies along the Path of Insight are the mind reflecting appearances and at the mind in relation to the body. An in-depth analysis of the objects of sensory perception leads to the conclusion that they are neither separate nor identical with whoever perceives them, and that they elude clear definition. A similar conclusion is drawn from the analysis of the mind in relation to the body. To quote Karmapa yet again:

Namely, you must decide that the body and mind are neither the same, nor different They are inseparable, like the reflection of the moon in water, being a unity of resplendence and śunyata, of appearance and sunyata. (9th Karmapa Wangchuk Dorje, 1993: 63) 
Beru Khyentse Rinpoche elaborates on this comparison and explains the nature of the said phenomenon in the following way:

If the reflection of the moon in a puddle and the puddle water were the same, then the phenomenon should remain, even if you place your hand on top of it. If they were separate, you should be able to remove the phenomenon from the puddle, just like you would remove a floating piece of paper. (Beru Khyentse Rinpoche, 1993: 63)

The recognition of the fundamental inseparability of the mind and phenomena, and of the mind and body is yet another insight into the true nature of the mind.

The final study in the meditation of penetrative insight refers to the nature of settled and 'moving' minds together. The practitioner should analyse whether the two are the same or different things. Following Karmapas explanation: "There is a big difference between the moving mind, which can think up anything and fantasies in endless variety, and the settled mind, which stays without moving" (9th Karmapa Wangchuk Dorje, 1993: 55).

In their analysis of the nature of thought, the practitioner should come to the conclusion that the two states of mind alternate. "When the mind is settled, nothing is moving, and when something is moving, the mind is moving as well". Thins in turn leads to the conclusion that in fact the nature of mind itself does not change, irrespective of the presence of thoughts on the one hand, or their absence on the other. Karmapa explains this issue with the following example "Like water and waves, it is the mind alone that functions and acts. That is all there is to it." (9th Karmapa Wangchuk Dorje, 1993: 55).

What the author suggests is that the mind can enter an unlimited number of different states, but all these activities are taking place within the same very mind, just like a disturbed surface of water does not change the quality of the water itself, nor does it make the water 'different' in any way. With the studies mentioned above, another process is set in motion. The progress in penetrative insight meditation is realised along a path of development called the Four yogas of Mahamudra, which are simultaneously the four stages related to certain levels of realisation. The following levels of realisation can be indicated (Ray, 2002: 279-283):

- One-pointedness; the fulfilment of this yoga grants the ability to remain undisturbed in concentration irrespective of other activities or circumstances, it is also the first recognition of the nature of mind;

- Simplicity; yoga realises a natural state of the essence of the mind, free from any conceptual reference, inclusive of categories such as 'the existence' or 
'the non-existence', which leads to their reassessment, to the understanding that they are complementary in defining their meanings, and to the perception that the internal realm of thoughts and the external realm of events are equally void, without an inherent existence (Skt. śunya);

- One taste; the realisation of this level means that the multitude of forms share the same nature, undifferentiated in its voidness; that 'samsara' and 'nirvana' are one; thus the practitioner transcends the subject-object opposition and realises that any such divisions are mere appearances; Objects and event in the world have no substance, due to which their 'taste' is always the same. It is an experience of the lack of any 'point of reference.' This level reaches beyond the formal meditation practice and refers to all mundane, daily activities;

- Non-meditation; fulfilling this yoga is where the continuous realisation of the unity of appearance and voidness, resplendence and voidness, bliss and voidness, begins. As a development on the one-taste level, it is where all dualities are transcended. The 'non-meditation' yoga is a realisation of the fruit, i.e. the goal of the practice, where what is achieved reaches beyond sensory barriers, (...) and no time and space divisions are perceived as real. It works in a continuous manner, here and now, drawing on the omniscience of the mind. (Lama O. Nydahl, 1999: 23)

The penetrative insight meditation initially concentrates on analysing the unsettled mind, i.e. the objects referring to bodily senses, without any mental activity. The following study of the nature of a settled mind also includes the analysis of the relation of the mind to phenomena and to the body. In fact, this study indicates the co-relation between the subject and the potential object of perception. The main danger at this stage, as mentioned by Karampa, is that the experience of subject-object unity, i.e. the unity of resplendence (and of clarity, bliss and appearance) and voidness can become conceptualised. As a result of which, only a subtle image of the said unity is achieved, instead of a direct experience of such a state. Thus, it is merely an artificial representation, accompanied by the false conviction that the true nature of the mind had already became clear (Skt. cittata, Tib. sems nyid). Being in possession of a mere intellectual pattern effectively hinders further development. Even though it might be helpful for a beginner, it is a considerable obstacle at the further stages of practice. In the Tibetan tradition, the introduction to the true nature of the mind is a responsibility of the master, the root teacher, who should choose an appropriate, non-premature moment. The root Guru helps the practitioner to recognise the nature of the mind or introduces them to the idea. The practitioner, however, 
must be prepared for this, capable of maintaining a non-conceptual quiescence of mind without the lapses into mental imaging. A qualified teacher will be able to notice this direct, or yet indirect experience. However, if this experience becomes embedded as the actual state of non-duality, it may become a subtle hindrance, effectively obscuring what has yet to be discovered. Beru Khjentse Rinpoche remarks on the following in the description of this hindrance: "To conceptualise about the lack of qualities of the non-conceptual state of mind is to go to an extreme of making non-existence into a "thing»" (Beru Khjentse Rinpoche, 1993: 61) and elsewhere: "There is just the resplendence of an appearance and Voidness, with no (truly existent) object." (9th Karmapa Wangchuk Dorje, 1993: 53).

In fact, the five situations which are the subject to analytical study can be narrowed to two states of mind: settled and moving. The essence of the former is the recognition of the nature of the mind itself, irrespective of appearing phenomena and events, while the latter is focused on the recognition of the nature of a moving mind, where mental activity is ongoing and various concepts become subtle phenomena, the nature of which should also be recognised. Karmapa concludes on the issue of these two states with a final statement that:

There is not even the slightest difference between the non-conceptual state and that of true insight into the fact that moving thoughts, the settled mind and the nature of thoughts themselves are all three clear, void and brilliant. To hold the two (as being different) is an interpolation of the mind that does not recognize them. (9th Karmapa Wangchuk Dorje, 1993: 62)

The author's final remark in the above fragment was apparently meant to pertain to the exact situation where a certain mental activity is present and, in an artificial manner, divides that which is primarily inseparable, by the means of conceptualisation. This phenomenon can be characterised from two different points of view. The resulting diagnosis, however, would be the same in both cases: (1) when we regard the issue from the perspective of the content of the very act, then the act is false, as it is a depiction of something that does not exist at all, but merely appears to exist; and (2) the very existence of the act obscures what is meant to be discovered and recognised. As can be concluded from the above, the necessary condition of being able to recognise this state is, firstly, the experience of the nature of the settled mind, and secondly, the realisation that in the case of emerging mental activity, the situation as such remains practically unaltered. It can be said, that from the perspective of the insight into the nature of mind itself, there 
remains the same subject-object relation, even if it reveals here its creative dynamics, realised as mental activity. Quite simply, if in this situation the thoughts as such are encompassed in meditation, they become the primary consciousness. As it would seem, the capacity to objectify one's own mental activity is crucial, since it allows for the avoidance of the conceptualisation of the nature of mind, and for the understanding of that, which had emerged as the movement of thoughts. The analytical study of a moving mind poses more of a cognitive challenge due to the subtle and shifting character of the emerging thoughts. This challenge lies in the fact that the recognition of the nature of the moving mind is tantamount to being able not to follow the thoughts nor to yield to them. To phrase it differently, what this means is that there emerges a subtle tendency to become attached to the content of thoughts, as to the objects and situations which are encompassed in these thoughts.

Thus, to conclude the above reflections upon the penetrative insight meditation, and to account for the required analytical studies above, it should be remarked that the issue of recognising the nature of the moving mind seems to be of crucial importance. Karmapa addresses this issue yet again in the context of recognising the nature of the settled and moving mind together. In its essence, this issue is not a different quality than the other analysed ones, but rather a greater level of complexity, where two states of mind, which had been analysed separately, are taken into account together and should be recognised as sharing the same nature. In actuality, it is only this situation that reflects, in all its dynamism, sophistication and subtlety of form, the daily life practice, where the states of the presence and lack of thoughts alternate. From the perspective of the structure of an act of cognition, the objective element is comprised alternately of sensory and mental objects, which, according to Buddhist teachings, are impermanent (Skt. anitja) and insubstantial (Skt. anatman) in status, i.e. they are void (Skt. śunya) and as such represent exactly the same level of cognitive content.

\section{Conclusion}

A synthetic presentation of the issue discussed above can be achieved with a diagram displaying certain general co-relations and structural elements with regards to the Path of Insight. Even though such a diagram may be a simplification, it can nevertheless be helpful to present the key issues described in this paper and portray them in the wider doctrinal context. 


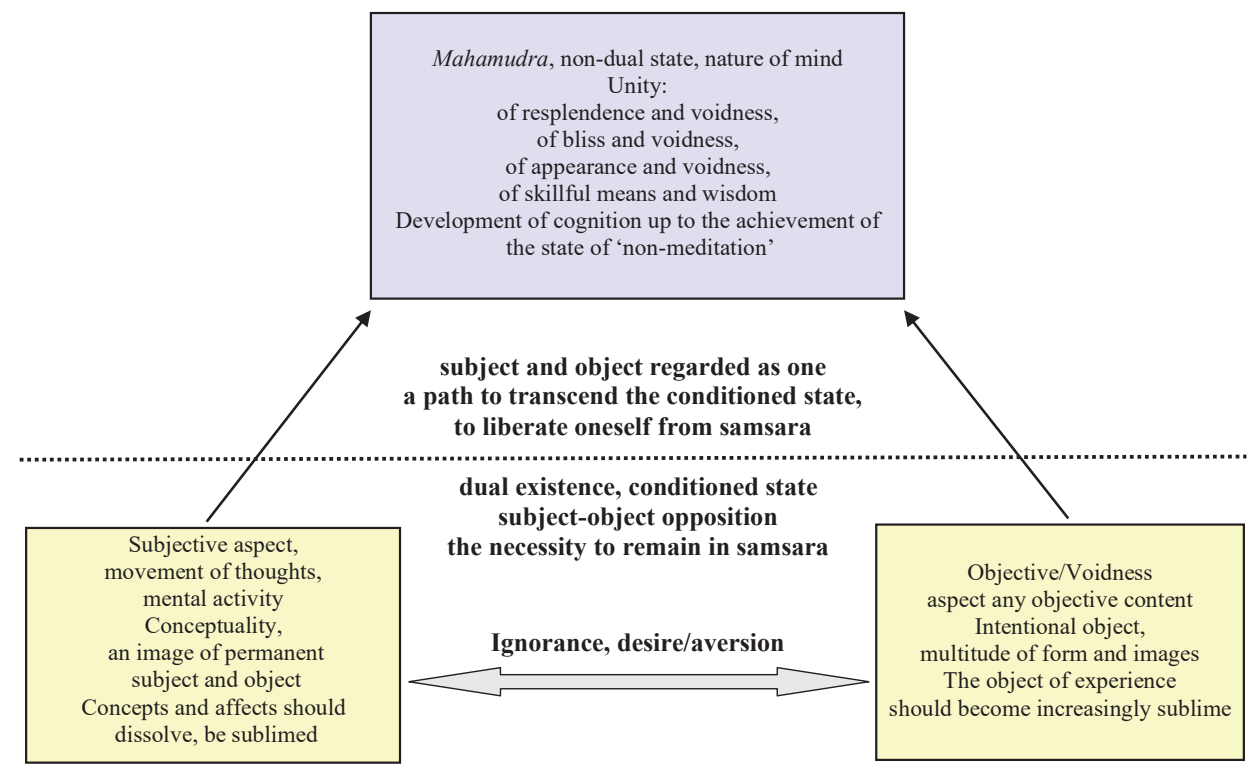

The task that a human being is faced with is formulated by the common preliminary practices, which indicate the necessity to enter upon a path of spiritual development. The extraordinary preliminaries on the other hand, result in a formal commitment to a certain heritage line of teaching and grant the capacities essential in the further core practice. The Path of Insight, or the Path of Liberation, is comprised of the said preliminary practices, followed by the mind tranquillity meditation and the penetrative insight meditation. Even though a formal threepart division is in use, the above mentioned techniques and meditation practices should be regarded as a unified process leading to the achievement of the non-dual state, or mahamudra. What is at hand here, is the recognition of the nature of mind, the realisation of it, the transcendence of the subject-object opposition in the cognitive sense, followed by the settlement, deepening and broadening this experience over the daily life events. The development goal of the individual spiritual practice is to achieve the state of 'non-meditation', which allows the adept to dwell within the nature of the mind in a continuous manner, irrespective of arising circumstances or their own external and internal activity.

As it would seem, the greatest challenge lies in the mastering and understanding of the nature of the 'moving mind', with regards to the cultivation of a variety of concepts, the emergence and movement of thoughts, as well as the occurrences of any kind of emotional turbulence. The exact significance of this issue varies, depending on the stage of practice to which it is related. In the case of mind tran- 
quillity meditation, a great difficulty arises with the occurrence of uncontrolled and manifold mental activity, which is an anathema to the very goal of the practice. With regards to the penetrative insight meditation, however, the obstacle on the path to success, due to the fact that the goal of this practice is inherently cognitive in nature, lies in the undesired maintenance of subtle concepts within the mind and in the attachment to any abstract notions. The above also pertains to certain preconceptions with regards to the ultimate goal of the practice, as well as its stimulation, which can only be beneficial and legitimate at the initial stage of meditation practice. Yet, any psychic or mental acts should never be denied or blocked. They should instead be regarded as the spontaneous activity of the mind; one which should not be 'followed' nor rejected, as all becomes a part of the 'path' and may be used as a means to reach its goal.

The key of the development of meditation practice, i.e. the progress along the Path of Insight, lies in the increasing concentration and one-pointedness, as well as in the growth of a certain power and depth of cognition of one's own, true, inherent nature, up to the postulated fulfilment, achieved in an 'effortless' manner. Otherwise speaking, it is a sublimation of experience both in the subjective and objective aspect, which signifies a process of the development of experiencing and perceiving, during the course of which the reference to oneself becomes sublime, along with the potential object of perception, up to the state where the single remaining 'object' of perception is the unity of subject and object. Experiencing the nature of mind itself lacks any kind of adequate description. The narrative, however, concentrates upon the transcendence of the subject-object dualism in its many aspects and on the varied levels of realisation of such a state, which can be summarised as the capacity to objectify both sensory observations, as well as any conceptualisations or one's own preconceptions. As is evident, it is these preconceptions that pose the greatest difficulty. Transcending this level is tantamount to the discovery of the meaning, to the cognition and experience of that, to which the most abstract categories of the system pertain. Which in turn marks the achievement of the soteriologic goal postulated by the given philosophical or religious system. With regards to the topic at hand, this goal lies in the unequivocal realisation of mahamudra, the ultimate fulfilment of the Path of Insight.

The issues discussed here with regards to this particular Path within the Tibetan Buddhism tradition are regarded from the epistemological, subject-to-object perspective, which is a horizontal one, and in which any situation is always regarded from the point of view of a subject remaining in a relation to a potential subject of cognition. Due to the above, the duality of internal and external experience is hardly applicable, as any event in general is regarded as inseparable from the sub- 
ject understood as an absolute. The practitioner can sacralise this subject by identifying with it in meditation practice, and discover within themselves the absolute condition, which by assumption transcends any narratives, and any experiences that the narratives may postulate. Thus, any postulated existence of an extrasubjective reality, whether conscious or subconscious, is inappropriate for soteriologic reasons. The same reasons result in the necessity to translate any ontological terms into epistemological ones. What is postulated here, however, is a certain type of 'weak', or even 'momentary' ontology, which arises due to the predicative nature of the language. As a consequence, the language, or any kind of narrative confines its referents into conceptions, thus endowing them with an apparent permanence. This is further 'secured' by the a priori assumption of the inherent impermanence and the inevitability of change (Skt. anitya, Tib. mi rtag pa) to which all existence is subject.

The Buddhist type of approach does possess a certain, distinct auto-soteriologic and subjective character, as opposed to, e.g. Christianity, or, more generally, any theist Western religion based on the Hebrew Bible. Viewed from the perspective of the Path of Insight described above, any of the (so-called) Religions of the Book fall into fundamental cognitive dualism, and as such are not yet soteriologically reliable. Without doubt, a literal reading of one's own belief system, or even the emphasis on systemic discrepancies between them, results in a tendency to create hierarchies of the spiritual and religious pursuits. Thus, in the contemporary era of dynamic amalgamation of cultures and worldviews, such an issue poses a major challenge to the followers of various religious systems.. In the case of mysticism however, given the validity of the spiritual experience which it postulates, the approach to such issues should be expressed in activities aimed at dialogue and mutual respect.

\section{Bibliography}

Beru Khyentse Rinpoche (1993), Komentarz do tekstu IX Karmapy, [in:] IX Karmapa Wangcziuk Dordże, Mahamudra eliminująca ciemności niewiedzy. Kraków (Year of the Water Rooster).

Brück M. von (1997a), Buddyzm, [in:] H. Waldenfels (ed.), Leksykon religii, Warszawa.

Brück M. von (1997b), Tantra/Tantryzm, [in:] H. Waldenfels (ed.), Leksykon religii, Warszawa. Chang G.C.C. (1987), Centralna nauka tantry tybetańskiej, [in:] J. Sieradzan (ed.). Buddyzm, Kraków. Dakpo Tashi Namgyal (2006), Mahāmudrā: The Moonlight. Quintessence of Mind and Meditation, Boston.

Eliade M. (1997), Joga. Nieśmiertelność i wolność, Warszawa.

Jakubczak K. (2003), Doświadczenie mistyczne w tradycji buddyjskiej, [in:] M. Jakubczak, M. Sacha-Piekło (eds.), Między wiarą a gnozą. Doświadczenie mistyczne w tradycjach Orientu, Kraków. 
IX Karmapa Wangcziuk Dordże (1993), Mahamudra eliminująca ciemności niewiedzy, Kraków (Year of the Water Rooster).

Keown D. (1997), Buddyzm, Warszawa.

Khenchen Thrangu Rinpoche (2003), The Ninth Karmapa's Ocean of Definitive Meaning, Ithaca.

Kosior K. (1996), Mistycyzm, [in:] J Dębowski, L. Gawor, S. Jedynak i in., Mała encyklopedia filozofii, Bydgoszcz.

Lama Tashi Namgyal. (2003), Introduction, [in:] Khenchen Thrangu Rinpoche, The Ninth Karmapa's Ocean of Definitive Meaning, Ithaca

Lozang Cziekyi Gyaltsen, I Panczen Lama (1995), Wielka Pieczęć Pustki, (Mahamudra Pustki), Kraków (Year of the Wood Pig).

Ngawang Dhargyey (1995). Komentarz do tekstu I Panczen Lamy, [In:] Lozang Cziekyi Gyaltsen, I Panczen Lama, Wielka Pieczęć Pustki, (Mahamudra Pustki). Kraków (Year of the Wood Pig).

Nydahl O. Lama (1999), Wielka pieczęć. Pogląd mahamudry buddyzmu Diamentowej Drogi, Gdańsk.

Podsiad A., Więckowski Z. (1983), Mały słownik terminów i pojęć filozoficznych, Warszawa.

Ray R.A. (2002), Secret of the Vajra World. The Tantric Buddhism of Tibet, vol. 2. Boston-London.

Tenga Rinpoche (1994), Sutry i tantry. Drogi buddyzmu, Kraków.

Traleg Rinpoche (2005), Mahamudra ocean pewności, Kraków (Year of the Water Rooster).

Zotz V. (2007), Historia filozofii buddyjskiej, Kraków. 
